\title{
UTAKOUUKSESA
}

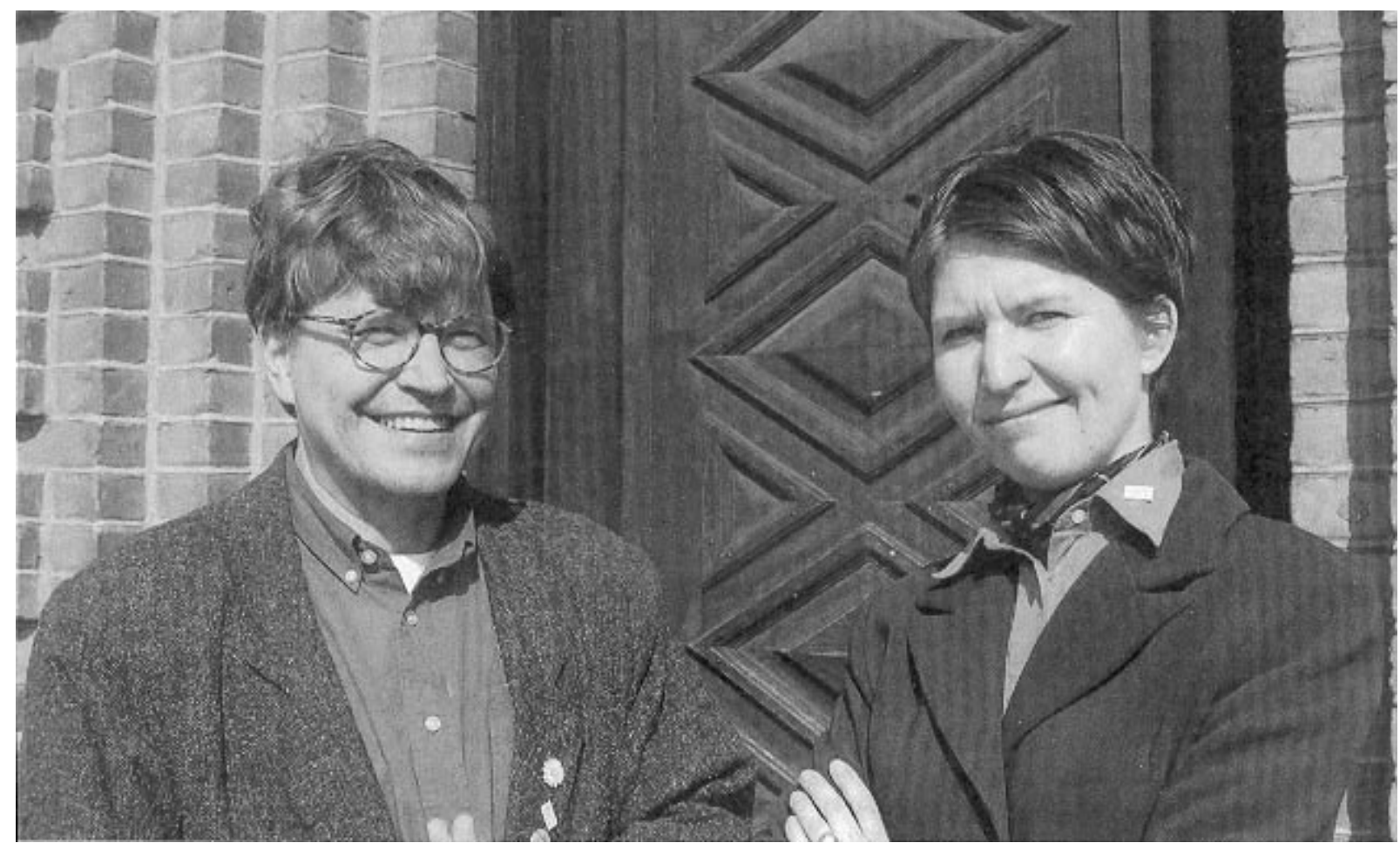

Timo Partanen ja Hanna Heikkinen ovat Tiimiakatemian vahva kaksikko.

\section{Tiimiakatemia - markkinoinnin, oppimisen ja yrittäjyyden keskus}

Tiimiakatemia on osa Jyväskylän ammattikorkeakoulua, sen markkinoinnin, yrittäjyyden ja elinikäisen oppimisen keskus. Sen väki pursuaa menestys- ja tulosuhoa. Mutta ei savua (uhoa) ilman tulta: työskentelytavan takana on vankka oppimisnäkemys. Tiimiakatemia on oppimiskeskus, jonka läpikokeneet ovat omaksuneet selkäytimiinsä tiimityöyhteisön kulttuurin ja työtavat.

Tiimiakatemian helmoissa syntyneen, nyt itsenäisen yrittäjäosuuskunnan Villimielen osakas $\mathrm{H}$ anna $\mathrm{H}$ eikkinen kiteyttää muutaman vuoden kokemuksensa Tiimiakatemiassa: "Tiimissä yksilö pääsee suoritustasossaan korkeammalle kuin luodessaan uraputkea yksin. Täällä treenataan huippuyksilöitä, ja parhaat tulokset saadaan joukkueena."
K aikki Tiimiakatemiasta "valmistuneet" ovat työllistyneet ongelmitta. Valmentajan Timo Partasen mukaan nuoret ovat erittäin kysyttyjä K eski-Suomen yritysmaailmassa, jopa kesken koulutuksen. Silti 30 prosenttia kolmivuotisen koulutuksen läpikäyneistä perustaa oman yrityksen, tiimi-idealla luonnollisesti. Sen vuoksi Partanen luonnehtiikin Tiimiakatemiaa pienyritys- 
hautomoksi. Tiimimäisten työskentelytapojen ja litteän organisaation ideaa on vaikeaa istuttaa vanhaan, vakiintuneeseen, vaikkakin kriisiytyneeseen yritykseen. O n mutkattomampaa aloittaa tuoreella liikeidealla ja yhdessä muiden tiimiajattelun omaksuneiden kanssa.

O piskelijoista ajatus "valmistumisesta" on absurdi. Tämä koulutus ja kokemus on yksi, joskin hyvin tärkeä vaihe heidän elämässään, mutta valmiita he eivät mielestään voi olla koskaan.

\section{Tiimioppimisen teoriaperusta}

I dea Tiimiakatemiasta syntyi vuonna 1992 toteutetun ammattikorkeakoulu-uudistuksen myötä.

- Olen opettanut markkinointia Jyväskylän kauppaoppilaitoksessa vuodesta 1973. Petyin ammattikorkeakouluun, kun huomasin, ettei mikään ollut muuttunut. Sitten tajusin, että kaikki on minusta itsestäni kiinni, kertoo Tiimiakatemian valmentaja Timo Partanen, yksikön esimies.

Ihan ensimmäiseksi ammattikorkeakoulusta vallattiin luokkahuone ja heitettiin pulpetit pois. Sieltä toiminta sai alkunsa vuoden 1993 alussa ensimmäisen tiimin aloittaessa toimintaa. I dea Tiimiakatemiasta, omasta oppimiskeskuksesta syntyi keväällä 1996, kun ensimmäiset tiimioppimismetodin kautta opiskelleet valmistuivat. Todeksi idea muuttui, kun tiimien toiminta siirrettiin uusiin tiloihin Schaumanin vanhan vaneritehtaan pääkonttoriin samana kesänä. Samaan aikaan syntyi ensimmäinen kimppayritys - Villimieli - jonka kautta osa valmistuneista tiimiläisistä työllisti itsensä. Toimitiloissa ei ole ainoatakaan tilaa, missä olisi pulpetteja tai perinteisiä luentotiloja. Miljöö kannustaa aivan uudenlaiseen vuorovaikutukseen, oppimiseen ja yrittäjämäiseen toimintaan.

Teoriaperusta nojaa kolmen tiedemiehen ajatteluun. Lähtökohtana on "tiimiguru" Peter Sergen kehittämä tiimioppimisen teoria. Sen mukaan tehokkain oppiminen syntyy suorassa kos- ketuksessa. 0 pitaan tekemällä. Tiimit syntyvät tavoitteiden ja tarpeiden ympärille. Ian Gunninghamilta on omaksuttu itseohjautuvan oppimisen teoria, ennen muuta oppimissolujen ajatus. Japanilaiselta Ikujiro Nanakalta on vuorostaan poimittu dokumentoinnin ja uuden tiedon synnyttämisen tärkeys.

\section{Todellisia projekteja tiimeiksi organisoituen}

Heti Tiimiakatemiaan tultaessa organisoidutaan tiimiksi. Tiimi alkaa välittömästi toteuttaa oikeita projekteja ja hankkeita oman yrityksen kautta. Projektien avulla opitut tiedot ja taidot testataan käytännössä. Tiimeihin jokainen hakeutuu oman kiinnostuksensa perusteella. Luontaisia taipumuksiaan ja ydinosaamistaan jokainen pääsee hyödyntämään ja kasvattamaan haluamissaan projekteissa.

Tätä nykyään toiminnassa olevat tiimit ovat Eliksiiri (tiimeistä nuorin), Termitit, Profiilis ja Idearitsa Nämä kaikki ovat osuuskuntia. Tiimiakatemian yhteydessä toimii myös yrityshautomo eli synnytyspaja valmistuneille tiimiläisille. Synnytyspajassa on tätä nykyään kolme yritystä: Villimieli, Festago-tapahtumapalvelut ja Visionikkarit. Y ritysten käynnistämistä edesauttaa tilojen ja toimintamahdollisuuksien saanti Tiimiakatemian suojista.

A iemmin toimivat myös Kampiaksdit ja Wisardit Ensimmäinen tiimi oli Round the World Team josta Hanna Heikkisen osalta kaikki itse asiassa alkoi:

- Näin jossakin ilmoitustaululla ilmoituksen, missä tiedusteltiin, olinko halukas lähtemään maailmanympärysmatkalle ja oppimaan siinä sivussa markkinointia. Wau! Totta kai minua kiinnosti päästä maailmalle. Siitä kaikki alkoi ja kolmen vuoden kuluttua lähdimme sitten matkalle hankittuamme omatoimisesti tiimiyrittäjyyden avulla matkarahat ja opittuamme paljon siinä sivussa.

- K aikki lähtee projekteista, joilla on selvät tavoitteet. Emme opettele tarpeettomia asioita, sanoo Timo Partanen. 


\section{WITKOUUTKSTA}

Tiimiakatemian tiimit vastaavat $\mathrm{mm}$. jokavuotisesta ammattikorkeakoulujen valtakunnallisesta suurtapahtumasta NETWORK 2000, joka järjestettiin nyt Jyväskylässä kolmannen kerran. Viimeksi päiville osallistui 5000 ammattikorkeakoululaista. K yseessä on siis massiivinen projekti. O piskelijat itse kuvaavat sitoutumistaan loppuvaiheessa jo uhrautumiseksi, sillä töitä tehdään minimaalisella yöunella ja yksityiselämä saa jäädä.

Termiitit -osuuskunnan harteilla on myös toinen suurtapahtuma, Sport Techno -98. Esimerkkinä kauaskantoisista ja suurista projekteista on myös vuonna 1993 käynnistetty "I hmiskasvoinen Jyväskylä" -projekti palvelutason ja asiakasystävällisyyden parantamiseksi. Projekti toteutui kolmena vuonna ja sai jatkoa "H yvän palvelun Jyväskylän" muodossa. Jatkoa nämä projektit ovat saaneet "Palveluaal to"-projektilla, jonka tavoitteena on nostaa Jyväskylän seudun palvelu Suomen parhaaksi. Tämä projekti kestää vuoteen 2000 asti.

K aikki tiimien projektit eivät ole yhtä massiivi- sia; jokainen tekee oman osaamisensa ja halunsa mukaan. Koko ajan on meneillään myös paljon pieniä projekteja, jotka ovat yhtä lailla oppimisen paikkoja.

- Aloitamme pienestä ja laajennamme vähitellen, kun osaamista karttuu. N yt projektien lähtötaso on jo paljon korkeampi kuin toiminnan alkaessa vuonna 1993.

$K$ un suuressa maailmassa tehdään uudelle tuotteelle kalliita markkinatutkimuksia, Jyväskylässä toimitaan toisin: saadaan idea ja aletaan toteuttaa sitä, testataan sitä käytännössä ja kehitetään teon aikana, tehdään virheitä ja opitaan niistä. Tiimiakatemialaiset kutsuvat virheiden tekoa "nousemiseksi pylly edellä puuhun".

O suuskunta Termiiteissä on yhteensä 14 osakasta. Jaana Hiltunen tekee parast'aikaa Sport Techno . 98:aa, Vilma Väisänen Kymppi Nainen -projektia (Himoksella 16.5.), Iltatori-projektia ja Jyväskylän kauppakeskusten somistusta koskevaa Visuaalinen markkinointi -projektia, Niko Airaksinen eri projektien graafista suunnittelua ja painotuotteita ja Aleksi Manninen Palveluaaltoa.

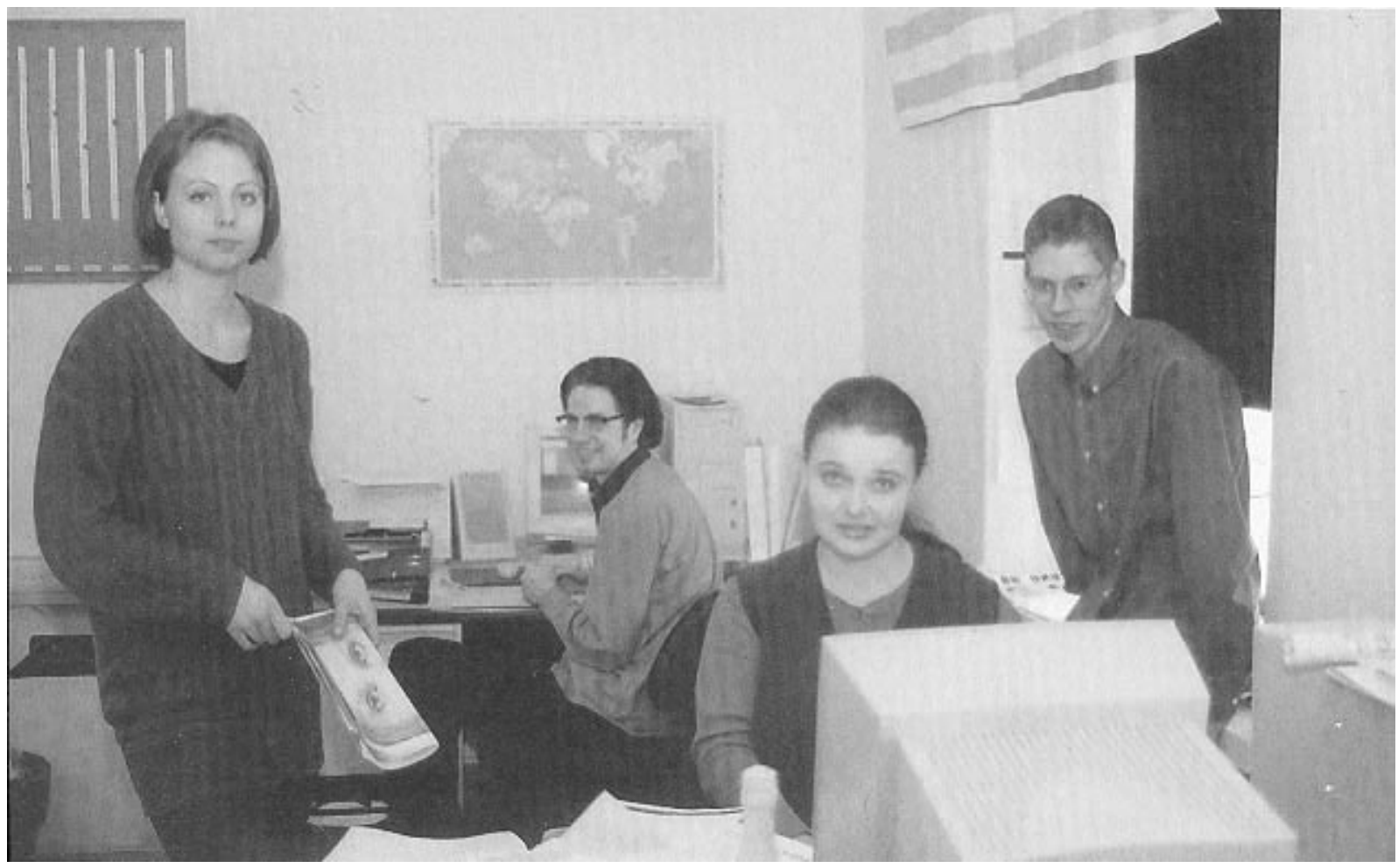




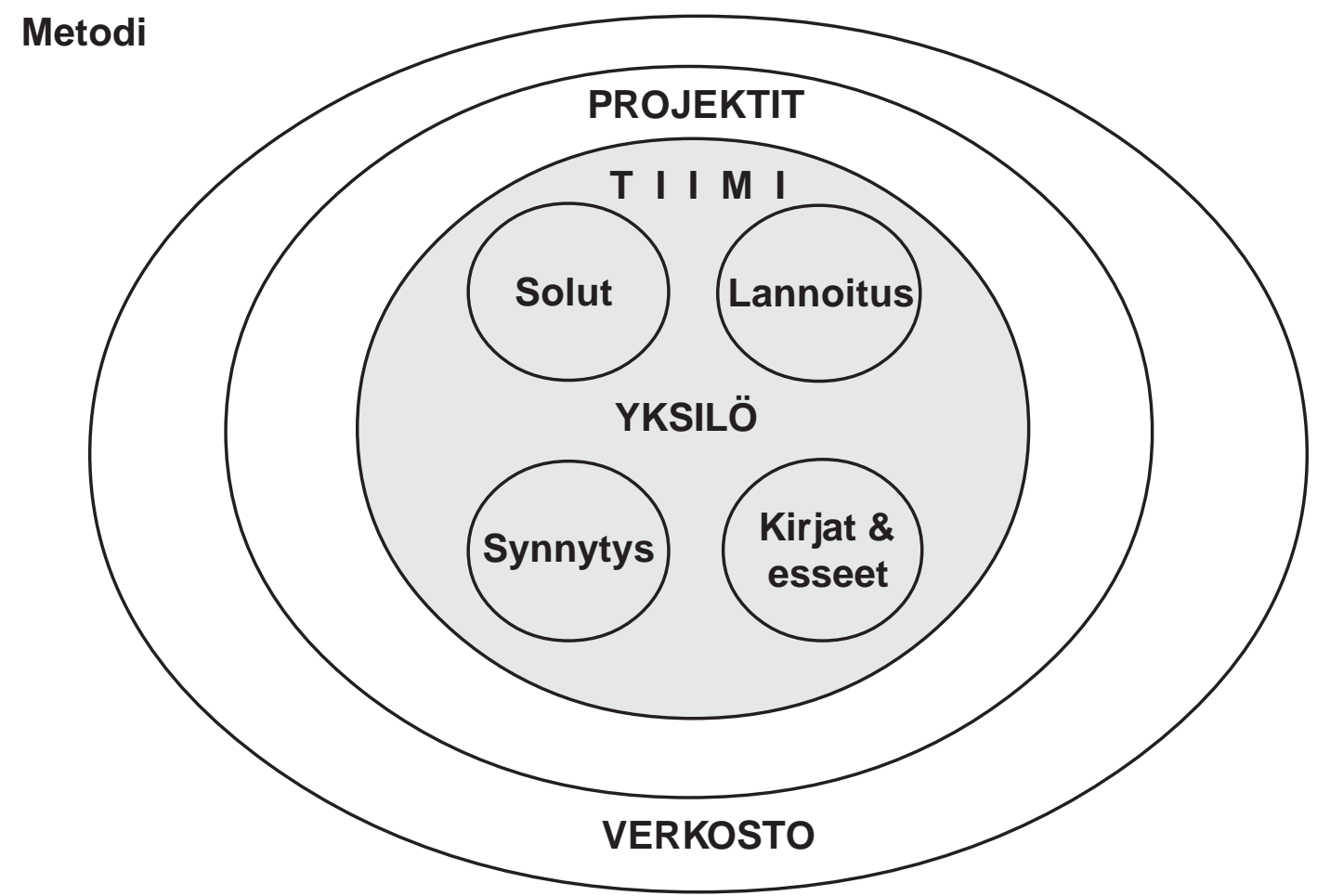

Mutta Timo Partanen uskoo vankasti siihen, että virheissä on juuri oppimisen paikka. "Sonyn perustaja A kio Morita on sanonut 99 prosenttia omasta oppimisestaan tulleen virheistä, ja hänellä oli sentään 50 vuoden kokemus oppimisesta. Hyviin tuloksiin pääsee oppimalla pienemmistä ja suuremmista virheistä."

\section{Käytäntö ja teoria käsikädessä}

Tiimiakatemiassa harjaannutetaan erilaisia taitoja, kuten päämäärätietoisuutta, oman osaamisen markkinointia, stressin ja muutoksen sietokykyä, luovuutta, oman persoonan kehittämistä, itsetuntoa, ryhmätyöskentelytaitoja ja sosiaalisia vuorovaikutustaitoja.

\section{Tiimityöskentelymalli}

- Litteä organisaatio elää visiosta. O n oltava päämäärä, tavoite, visio, sanoo Timo Partanen.

Tiimiakatemiassa perinteiset luennot on korvattu Iannoituksilla. Jokainen tiimi kokoontuu kaksi kertaa viikossa koko tiimin yhteiseen istuntoon. Lannoituksessa tärkeintä on reflektointi ja dialogiharjoitukset - opitaan toinen toiselta keskustellen, kuunnellen ja ajatuksia vaihtaen. Aika ajoin lannoituksiin haetaan uutta potkua ulkopuolisten asiantuntijoiden ja herättelijöiden avulla.

Lannoitusten rinnalla toimivat toinen toiselta oppimista tehostavat oppimissolut. Solu on 5-6 hengen oppimisyhteisö. Solujen tarkoituksena on antaa mahdollisuus vaihtaa ajatuksia, anaIysoida teorioita ja testata omien ajatusten kantavuutta.

0 ppimissoluissa käsitellään luettuja teoriakirjoja ja niistä kirjoitettuja essetä. Partanen korostaa voimakkaasti lukemisen ja kirjallisuuden seuraamisen tärkeyttä. K irjoja ei omaksuta sellaisenaan, vaan tärkeintä on, että niistä saadaan ajatuksia ja ideoita, joita voidaan testata projekteissa. K irjat antavat myös hyvää aineistoa yhteisiin keskusteluihin lannoituksissa ja soluissa. Tiimiläisiä patistetaan lukemaan vähintään kirja viikossa markkinoinnista, oppimisesta, 


\section{UTAKOUUTUESTA}

johtamisesta, innovoinnista ja tiimityöstä. A puvälineinä hyvien kirjojen valitsemiseen toimii mm. 365 kirjaa sisältävä kirjallisuusluettelo.

N ormaali tenttikäytäntö korvattiin ensin näyttökokeella ja sen jälkeen uuden synnytykselä O ppimissolun valmisteleman synnytyksen tarkoituksena on saada koko tiimi oppimaan soIun oppien pohjalta. Synnytys sanana kuvaa uuden tiedon synnyttämisen tärkeyttä - ei vanhojen tietojen keräämistä ja ulkoa oppimista. Tärkeää on ymmärtää jokaisen oppivan itseään varten. Tärkeää tiimityössä on käsite ydinosaaminen. On tärkeää, että tiimi hyödyntää jäsentensä vahvuuksia ja jokaisen ydinosaaminen tunnistetaan oppimisprosessin myötä.

Viimeisen vuoden aikana on pyritty kasvattamaan tiimien välistä vuorovaikutusta. Tätä kutsutaan Tiimiakatemian termistön mukaan ristipölytykseksi. Ristipölytyksen avulla vahvistetaan entistä enemmän toinen toiselta oppimista yhdistämällä projekteissa esimerkiksi kokeneempia ja kokemattomampia oppijoita toimi- maan yhdessä. $N$ äin toteutetaan vanhaa mestari-kisälli-oppipoika -mallia.

Sekä Tiimiakatemia että sen kehittämä 50 opintoviikon markkinoinnin MBA-ohjelma käyttävät seuraavia oppimisen työkaluja:

\section{Sivullisena lannoitusistunnossa}

Tiimiakatemiassa vieraillessani oli meneillään I dearitsan viikottainen lannoitus. O piskelijoilta sinkoili puoliympyränmuotoisessa keskustelutilanteessa sekä itsekritiikkiä että innostusta: O Itiin harmistuneita siitä, että niin moni lannoitustilaisuudessa on passiivinen vapaamatkustaja tai tunnustettiin, että solun idea on vuodenkin kokemuksen jälkeen jäänyt hämäräksi. Motivoiduttiin lukemaan oman alan teoriakirjallisuutta, oivallettiin solun tärkeys ja koettiin itsestä välitettävän, kun valmentaja oli soittanut jokaiselle kotiin.

\section{Oppimisen työkalut}
Yhteiset
1. tiimi
2. solu
3. Iannoitukset
4. oppimisen arviointi
5. projektit
6. verkostot
7. yhteinen haaste
8. reflektio
9. Tiimiakatemia

H enkilökohtaiset
1. kirjat
2. esseet
3. opiskelukartta
4. treenipäiväkirja
5. oppimissopimus
6. oma pyrkimys
7. dialogi

Oppimisperusta

- hyvä oppimisympäristö

- oppiminen toinen toiselta

- jatkuva kehittäminen

- oppia arvioimaan itseään ja toinen toistaan

- jatkuvat kokeilut

- kontaktien lisääminen

- luo kulttuurin ja muotouttaa tiimin

- oppia kokemuksesta ja ymmärtää toisten ajattelua

- laboratorio, jossa testataan uusia menetelmiä ja ajatuksia

- 50-100 hyvää ja monipuolista kirjaa markkinoinnista ja johtamisesta

- omat kolahdukset projekteihin

- henkilökohtainen opintosuunnitelma

- opiskelun kurinalaisuus ja edistyminen

- ydinlupauksen kautta vastuu omista opinnoista

- halu tehdä parhaansa

- oppia kyselemään ja kuuntelemaan 


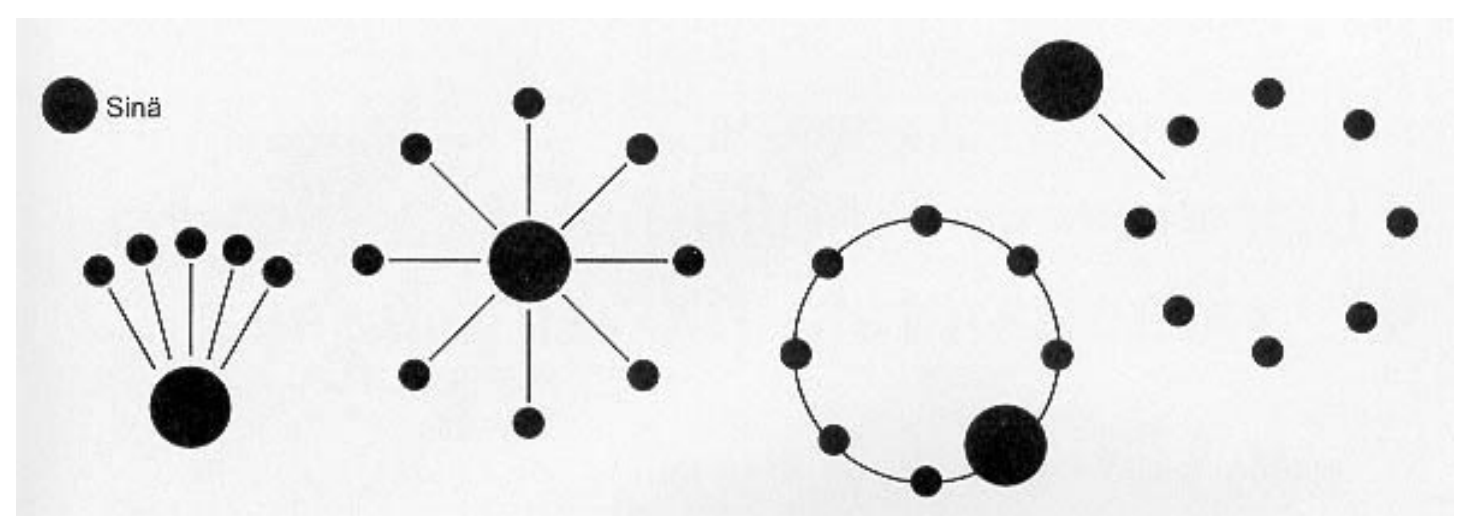

Tiimiakatemian 0 pettajasta vastuuvalmentajaksi -koulutusohjelma O VA näkee polun opettajasta yksin to imijajana eri vaiheiden kautta tiimin valmentajaksi näin.

"Tuli tunne, että solut ovat ihan jees, eivätkä mitään riippakiviä." "E i se riitä, että tehdään hyviä juttuja, vaan täytyy olla myös teoriapohjaa." "I tse itselleen asettama vaatimustaso nousee koko ajan" "E i tekemisellä pelkästään opita, eikä pelkällä lukemisella, vaan niitä yhdistämällä." "Tällaisessa opiskelussa me opitaan kuuntelemaan ja sitä kautta kyseenalaistamaan. Perinteisessä opiskelussa kyseenalaistus saa aikaan hermostumisen, oli kyseessä opettaja tai opiskelija näkemyksineen" "E nnen me luettiin tenttiä tai todistuksen numeroa varten, ei oppiaksemme." "Tiimityöskentelyssä oppii ihan väkisten verkostojen luontiin ja verkostojen käyttöön." "Sitoutuminen tulee ihan luonnostaan, kun projekti tuo vastuun."

O piskelijat ovatkin tyytyväisinä panneet merkille sen, että N okian henkilökunnaltaan edelIyttämien kvalifikaatioiden listalta Tiimiakatemian koulutuksesta löytyy kaikki. K oulu seuraa omaa edistymistään arviointimittarilla, joka on sovellutus Suomen laatupalkinnosta ja Malcolm Baldridge - palkinnosta. Siinä arvioitavana on tusinan verran erilaisia osatekijöitä. Pistemäärä on nykyään 405 ja tähtäimessä on kolmen vuoden päästä lähes kaksinkertaistettu, kansainvälisestikin huipputulos.

Viime vuonna Tiimiakatemia oli Tuottava idea -kilpailun yhteiskuntasarjan voittaja. V uosittaisen palkinnon takana on Suomen N uorkauppakamari yhdessä $\mathrm{K}$ auppalehden ja M erita-pankin kanssa.

\section{Schaumanin aivotehdas on POP}

K un Wilhelm Schauman perusti sata vuotta sitten vaneritehtaansa ja pääkonttorinsa Jyväskylän ja Jyväsjärven väliin, oli hän oman aikansa edistyksellinen. $\mathrm{N}$ yt patruuna Schauman on teollisuushistoriaa. Tiimiakatemia uskoo olevansa uuden vuosituhannen edistyksellinen "aivotehdas", yrityshautomo Schaumanin kunniakkaassa teollisuusmaisemassa. $K$ un viereen valmistuu Jyväskylän uusi messu- ja kongressikeskus, sen liepeillä on suuri kysyntä erilaisille oheispalveluille ja pienyrittäjille. Niitä Tiimiakatemia tietää tupsauttelevansa nuoruudenintoa, osaamista, omatoimisuutta ja itseluottamusta uhkuvien entisten opiskelijoittensa luomina uusina pienyrityksinä.

Jyväskylän Tiimiakatemia on ammattikorkeakoulun markkinoinnin ja yrittäjyyden linjana Suomessa ainoa, jonka oppiminen rakentuu tiimityöskentelylle. Jyväskyläläisten kokemus on se, että tiimiajattelua ei omaksuta suoraviivaisesti: tarvitaan arviolta 300-350 tuntia kollektiivista harjoittelua, jotta kollektiivisen ajattelun valmiudet tässä yksilöllisyyttä ja yksintekemistä juurruttavassa yrittäjyyskulttuurissamme on omaksuttu ja kehittyneet. Tiimiorganisaatioon siirtyminen pikakoulutuksen kautta ei siten vaikuta vakuuttavalta. 